\title{
Blood cultures in ambulatory patients who are discharged from emergency with community-acquired pneumonia
}

\author{
Thomas J Marrie MD
}

TJ Marrie. Blood cultures in ambulatory patients who are discharged from emergency with community-acquired pneumonia. Can J Infect Dis 2004;15(1):21-24.

OBJECTIVES: To determine the factors that predict whether or not ambulatory patients with community-acquired pneumonia (CAP) treated in an emergency room (ER) setting will have blood cultures drawn and the factors that predict a positive blood culture.

METHODS: Prospective observational study of all patients with a diagnosis of CAP, as made by an ER physician, who presented to any of seven Edmonton-area ERs over a two-year period.

RESULTS: Seven hundred ninety-three (19.2\%) of 4124 patients with CAP had blood cultures drawn. The site-specific blood culture rates ranged from $7.8 \%$ to $25 \%(\mathrm{P}<0.001)$; 41 of $793(5.1 \%)$ were positive. Streptococcus pneumoniae accounted for $58.5 \%$ of the isolates while Staphylococcus aureus and Escherichia coli each accounted for $14.6 \%$, or six patients each. Only two of the 24 patients with S pneumoniae bacteremia were subsequently admitted to hospital while all six of the patients with $S$ aureus were admitted. Only one of the six patients with E coli bacteremia was treated at home. No factors were predictive of positive blood cultures on multivariate analysis.

CONCLUSIONS: Physicians are selective in ordering blood cultures on patients with ambulatory pneumonia who present to an ER, and the positivity rate of $5.1 \%$ is quite high. No factors are predictive of positive blood cultures on multivariate analysis, thus clinical judgment has to prevail in the decision to perform blood cultures. Breakthrough bacteremia can occur with microorganisms susceptible to the antibiotics that the patient is receiving.

Key Words: Ambulatory; Blood cultures; Community-acquired pneumonia; Streptococcus pneumoniae
Des analyses sanguines chez les patients ambulatoires atteints d'une pneumonie d'origine communautaire qui reçoivent leur congé de l'urgence

OBJECTIFS : Déterminer les facteurs qui prédisent si les patients ambulatoires atteints d'une pneumonie d'origine communautaire (POC) traités à l'urgence subiront une analyse sanguine et les facteurs qui prédisent une analyse positive.

MÉTHODOLOGIE : Étude prospective par observation de tous les patients chez qui un médecin d'urgence a diagnostiqué une POC et qui se sont présentés à l'une des sept urgences de la région d'Edmonton au cours d'une période de deux ans.

RÉSULTATS : Sept cent quatre-vingt-treize (19,2\%) des 4124 patients atteints d'une POC ont subi une analyse sanguine. Les taux de culture selon l'établissement variaient entre $7,8 \%$ et $25 \%(\mathrm{P}<0,001)$, et 41 de ces $793(5,1 \%)$ analyses étaient positives. Le Streptococcus pneumoniae représentait 58,5 \% des isolats, tandis que le Staphylococcus aureus et l'Escherichia coli en représentaient chacun 14,6\%, ou six patients chacun. Seulement deux des 24 patients atteints d'une bactériémie à S pneumoniae ont finalement été hospitalisés, tandis que les six patients atteints de $S$ aureus l'ont tous été. Un seul des six patients atteints de bactériémie à E coli a été traité à domicile. Aucun facteur n'était prédictif d'une analyse sanguine positive à l'analyse multivariée.

CONCLUSIONS : Les médecins sont sélectifs au moment de demander que les patients atteints d'une POC qui se présentent à l'urgence subissent une analyse sanguine, et le taux de positivité de 5,1\% est plutôt élevé. Aucun facteur n'est prédictif d'une analyse sanguine positive à l'analyse multivariée. C'est pourquoi le jugement clinique doit prévaloir dans la décision de procéder à une analyse sanguine. Une bactériémie peut percer en raison d'une susceptibilité des microorganismes aux antibiotiques que reçoit le patient.
$\mathrm{B}^{\mathrm{l}}$ ood cultures are recommended as part of the diagnostic workup for patients with community-acquired pneumonia (CAP) who are admitted to hospital for treatment, and the positivity rate is in the range of $11 \%(1,2)$. However, there is some uncertainty about the role of blood cultures in patients who are seen in an emergency room (ER) with pneumonia and are well enough to be sent home. The recently published American Thoracic Society Guidelines for the management of adults with community-acquired pneumonia (2) do not mention blood cultures as part of the recommended testing for patients with CAP managed out of hospital. The Canadian
Infectious Diseases Society and Canadian Thoracic Society expert panel indicated that the precise incidence of bacteremia in patients with CAP managed on an ambulatory basis is unknown, but that it is lower than in patients who require admission to hospital for treatment of CAP (3). The Infectious Diseases Society of America guidelines for the management of CAP in adults (4) do not indicate that blood cultures should be part of the workup of patients with CAP who are to be managed on an ambulatory basis. These guidelines encompass the spectrum of patients with ambulatory pneumonia, the majority of whom are managed in a physician's office, and the remainder

Department of Medicine, University of Alberta, Edmonton, Alberta

Correspondence: Dr Thomas J Marrie, 2F1.30 Walter C Mackenzie Health Sciences Centre, 8840112 Street, Edmonton, Alberta T6G $2 B 7$.

Telephone 780-407-6234, fax 780-407-3132, e-mail tom.marrie@ualberta.ca

Received for publication September 11, 2003. Accepted November 9, 2003 
TABLE 1

Comparison of demographic features, symptoms and comorbidities for ambulatory patients with communityacquired pneumonia who had blood cultures done versus those who did not have blood cultures done

\begin{tabular}{|c|c|c|c|c|c|}
\hline \multirow[b]{2}{*}{ Demographic feature } & \multicolumn{2}{|c|}{$\begin{array}{c}\text { Done } \\
(n=793)\end{array}$} & \multicolumn{2}{|c|}{$\begin{array}{l}\text { Not done } \\
(n=3231)\end{array}$} & \multirow[t]{2}{*}{$\mathbf{P}$} \\
\hline & & & & & \\
\hline Mean age - years (SD) & 53.9 & $(20.2)$ & 52 & $(20.2)$ & 0.018 \\
\hline Male, number (\%) & 465 & $(58.8)$ & 1707 & $(52.9)$ & 0.003 \\
\hline Site of presentation & & & & & 0.001 \\
\hline A & 131 & $(25 \%)$ & 391 & $(75 \%)$ & 0.001 \\
\hline B & 26 & $(7.8 \%)$ & 304 & $(92.2 \%)$ & \\
\hline C & 106 & $(20 \%)$ & 424 & $(80 \%)$ & \\
\hline D & 125 & $(17.2 \%)$ & 600 & $(82.8 \%)$ & \\
\hline$E$ & 189 & $(20.7 \%)$ & 710 & $(79.3 \%)$ & \\
\hline $\mathrm{F}$ & 120 & $(21.9 \%)$ & 427 & $(87.1 \%)$ & \\
\hline G & 96 & $(20.3 \%$ & 375 & $(79.7 \%)$ & \\
\hline $\begin{array}{c}\text { Radiologist read CXR } \\
\text { as pneumonia (\%) }\end{array}$ & $409 / 767$ & $(53.3)$ & $1238 / 2984$ & $(41.5)$ & 0.001 \\
\hline Fever & 521 & $(65.7)$ & 1309 & $(40.5)$ & 0.001 \\
\hline Myalgias & 132 & $(16.6)$ & 344 & $(10.6)$ & 0.001 \\
\hline Shaking chills & 237 & $(29.9)$ & 576 & $(17.8)$ & 0.001 \\
\hline Cough & 599 & $(75.5)$ & 2591 & $(80.2)$ & 0.004 \\
\hline Sputum production & 339 & $(42.7)$ & 1606 & $(49.7)$ & 0.001 \\
\hline Altered mental state & 40 & $(5.0)$ & 66 & $(2.0)$ & 0.001 \\
\hline Nausea & 142 & (17.9) & 334 & $(10.3)$ & 0.001 \\
\hline Vomiting & 133 & $(16.8)$ & 334 & $(10.3)$ & 0.001 \\
\hline Wheeze & 120 & $(15.1)$ & 638 & $(19.7)$ & 0.003 \\
\hline \multicolumn{6}{|l|}{ Comorbidities } \\
\hline Cerebrovascular disease & 31 & (3.9) & 67 & $(2.1)$ & 0.003 \\
\hline Neoplastic disease & 35 & $(4.4)$ & 90 & $(2.8)$ & 0.018 \\
\hline Renal disease & 39 & $(4.9)$ & 71 & $(2.2)$ & 0.001 \\
\hline $\begin{array}{l}\text { Chronic renal failure } \\
\text { requiring dialysis }\end{array}$ & 11 & $(1.4)$ & 15 & $(0.5)$ & 0.004 \\
\hline Seizures & 24 & $(3.0)$ & 45 & $(1.4)$ & 0.001 \\
\hline Dementia & 23 & $(2.9)$ & 35 & $(1.1)$ & 0.001 \\
\hline $\begin{array}{l}\text { Antibiotics given before } \\
\text { presentation }\end{array}$ & $114 / 784$ & $(14.5)$ & $627 / 3214$ & $(19.5)$ & 0.001 \\
\hline Functional status & \multicolumn{2}{|c|}{$\mathrm{n}=\mathbf{7 1 7}$} & \multicolumn{2}{|c|}{$\mathrm{n}=\mathbf{2 9 2 0}$} & 0.001 \\
\hline Walking with no problems & 639 & $(89.1)$ & 2757 & $(94.4)$ & 0.001 \\
\hline $\begin{array}{l}\text { Walking with assistance } \\
\text { (cane, walker, person as }\end{array}$ & sisted) $^{38}$ & $(5.3)$ & 95 & $(3.3)$ & \\
\hline Bedridden & 12 & $(1.7)$ & 17 & $(0.6)$ & \\
\hline Wheelchair bound & 28 & (3.9) & 51 & $(1.7)$ & \\
\hline
\end{tabular}

CXR Chest radiograph

who are seen in an ER setting, evaluated and sent home. It is the latter population that we chose to study in the present study. Our objectives were to determine the factors that led ER physicians to draw blood cultures in patients who presented with pneumonia and to determine if there are factors that can predict a positive blood culture.

\section{METHODS}

From November 15, 2000 through November 14, 2002, all patients who presented to any of the seven ERs in Edmonton (Capital health region) and had a diagnosis of CAP made by the ER physician were managed according to a critical pathway for
CAP (1). The portion of this pathway that dealt with patients who were to be managed on an ambulatory basis included an information pamphlet for patients and recommendations for antimicrobial therapy based on Canadian guidelines (1). The pamphlet indicated when patients should notice improvement, what to do if they were not improving and warning signs that should prompt follow-up with a physician. In addition, they were to expect a phone call from one of the pneumonia nurses. Any diagnostic workup was left entirely to the discretion of the attending physicians.

Blood cultures, which were preformed at the discretion of the ER physician, were processed in two microbiology laboratories that served these seven hospitals. Identification of microorganisms was according to standard methods.

Capital Health Region (Edmonton, Alberta) is considered one of the largest integrated health systems in Canada. It serves approximately one million people and has an annual health budget of almost two billion dollars. There were 353,930 visits to the ERs in the Capital Health Region during the first year of this study and 360,959 visits during the second year of the study.

\section{Data analysis}

Data were entered into SPSS version 11 (SPSS Inc, USA). Because the continuous variables were not normally distributed, means of continuous variables were compared using the MannWhitney U test (5). Proportions were compared using Pearson's $\chi^{2}$ test. Multivariable analysis was done by entering factors that were significant at $\mathrm{P}<0.05$ on univariable analysis into a backward stepwise logistic regression procedure.

\section{RESULTS}

The site-specific blood culture rates ranged from $7.8 \%$ at site B to $25 \%$ at site A. Apart from site B, the blood culture rates at the other hospitals were remarkably similar, at $17.2 \%, 20.3 \%, 20 \%$, $21 \%$ and $21.9 \%$ for sites D, G, C, E and F, respectively (Table 1). Table 1 also shows that patients who had blood cultures done were older and more likely to have the radiologist read the chest radiograph as pneumonia, to have more symptoms and to have more comorbid illnesses. They were also more likely to be functionally impaired. They were less likely to have cough and produce sputum. They were also less likely to be receiving antibiotics at the time of presentation. Table 2 indicates that patients who had blood cultures done had greater abnormalities of vital signs and selected laboratory data.

Forty-one (5.1\%) of the 793 patients who had blood cultures done had a positive result. Patients who had blood cultures positive for a pathogen are compared with those who had negative blood cultures in Table 3. It is noteworthy that only the symptoms of nausea, vomiting and diarrhea, and a history of alcohol abuse were more common in patients with positive blood cultures. Table 4 indicates that the patients with positive blood cultures had a higher respiratory rate, lower systolic blood pressure and higher white blood cell count.

Table 5 gives the results of a multivariate analysis to determine factors that are predictive of a positive blood culture. There were no factors predictive of a positive blood culture. Failure to produce sputum was a negative predictive factor.

Table 6 indicates that Streptococcus pneumoniae was the most common organism isolated from the blood, accounting for $58.5 \%$ of the isolates while Staphylococcus aureus and Escherichia coli each accounted for $14.6 \%$ of the isolates. Table 6 also indicates how many of the patients with each microorgan- 
TABLE 2

Comparison of selected physical findings and laboratory data for patients who did and did not have blood cultures performed

\begin{tabular}{lrlcc}
\hline & \multicolumn{1}{c}{ Done } & Not done & P \\
\hline Mean temperature, ${ }^{\circ} \mathrm{C}$ & $38.0(1.1)$ & $37.1(1.0)$ & 0.001 \\
Mean pulse rate, beats/min & 102.8 & $(20.5)$ & $93.4(19.1)$ & 0.001 \\
Mean respiratory rate, breaths/min & 23.2 & $(6.2)$ & $21.7(5.1)$ & 0.001 \\
Mean systolic blood pressure, $\mathrm{mmHg}$ & 130.8 & $(23.3)$ & $131.2(22.2)$ & 0.688 \\
Mean diastolic blood pressure, $\mathrm{mmHg}$ & 75.4 & $(14.2)$ & $77.3(13.3)$ & 0.001 \\
Mean oxygen saturation (\%) & 93.6 & $(5.0)$ & $94.7(3.8)$ & 0.001 \\
Mean WBC (x10 $/ \mathrm{L})$ & 12.2 & $(6.4)$ & $10.9(5.2)$ & 0.001
\end{tabular}

Numbers in brackets indicate standard deviations. WBC White blood cell count

\section{TABLE 3}

Comparison of demographic features, symptoms and comorbidities for patients with community-acquired pneumonia who had positive blood cultures with those who had negative blood cultures.

\begin{tabular}{|c|c|c|c|}
\hline & \multicolumn{2}{|c|}{ Blood culture } & \multirow[b]{2}{*}{$\mathbf{P}$} \\
\hline & $\begin{array}{l}\text { Positive } \\
(n=41)\end{array}$ & $\begin{array}{c}\text { Negative } \\
(n=752)\end{array}$ & \\
\hline Male, number (\%) & $24(58.5)$ & $441(58.8)$ & 0.973 \\
\hline Radiologist read CXR as pneumonia & 28/39 (71.8) & $381 / 728(52.3)$ & 0.053 \\
\hline Sputum production & $10(24.4)$ & $329(43.8)$ & 0.015 \\
\hline Nausea & $15(36.6)$ & $127(16.9)$ & 0.001 \\
\hline Vomiting & $14(34.1)$ & $119(15.8)$ & 0.002 \\
\hline Diarrhea & $5(12.2)$ & $30(4.0)$ & 0.013 \\
\hline
\end{tabular}

Numbers in brackets indicate per cent. CXR Chest radiograph

ism were subsequently admitted to hospital. Only two of the 24 with $S$ pneumoniae were subsequently admitted. Ten of the 24 were reassessed in the ER and were improving and were sent home. Seven had no follow-up and could not be reached by phone. Five were doing well when contacted by phone. All of the patients with $S$ aureus bacteremia were admitted. One patient with E coli bacteremic pneumonia was successfully treated at home, one died in the ER and four were admitted after assessment for the positive blood culture.

Seven bacteremic patients were receiving antibiotics at the time of presentation (Table 7). Three of the isolates were $S$ pneumoniae, two were $S$ aureus and two were $E$ coli. All three patients with $S$ pneumoniae were reassessed and discharged from the ER with a different antibiotic than the one they were receiving at time of presentation. The patient with $S$ aureus was sent home on the same antibiotic, azithromycin, that had been started earlier that day by his family doctor. He was reassessed once the blood culture result was known and at that time he was admitted. Susceptibility testing revealed that the three $S$ pneumoniae isolates were susceptible to the initial antibiotic therapy and indeed were susceptible to penicillin, cefuroxime, erythromycin, clindamycin, ofloxacin, trimethoprim-sulfamethoxazole and vancomycin.

\section{DISCUSSION}

In a study of patients with community-acquired pneumonia treated in an ambulatory setting carried out in Pittsburgh, Boston and Halifax, 15 (7.7\%) of 197 patients who presented to non-ER settings (mostly physician offices) had blood cultures done while $40(21.4 \%)$ of 197 patients who presented to ERs had blood cultures done (6). In the present study, 19.2\% of
TABLE 4

Comparison of selected physical findings and laboratory data for patients with positive and negative blood cultures

\begin{tabular}{lcrcc}
\hline & \multicolumn{3}{c}{ Blood culture } \\
& Positive & Negative & $\mathbf{P}$ \\
\hline Mean age & $48.4(18.3)$ & $54.2(20.2)$ & 0.075 \\
Mean pulse rate & $111.5(24.1)$ & $102.3(20.2)$ & 0.005 \\
Mean systolic blood pressure & $120.9(24.9)$ & $131.3(23.2)$ & 0.007 \\
Mean WBC (x109/L) & $15.1(6.9)$ & $12.0(6.4)$ & 0.004 \\
\hline
\end{tabular}

Numbers in brackets indicate standard deviations. WBC White blood cell count

TABLE 5

Multivariate analysis of factors that predict a positive blood culture in ambulatory patients with communityacquired pneumonia

\begin{tabular}{lcccc}
\hline & Odds ratio & Lower & Upper & $\mathbf{P}$ \\
\hline Age group & & & & \\
$\quad<25$ vs $>65$ (years) & 1.432 & 0.351 & 5.848 & 0.617 \\
$25-65$ vs $>65$ (years) & 1.735 & 0.753 & 3.997 & 0.196 \\
Male & 0.963 & 0.499 & 1.857 & 0.909 \\
Fever & 1.347 & 0.608 & 2.984 & 0.463 \\
Myalgias & 1.256 & 0.578 & 2.729 & 0.565 \\
Sputum production & 0.400 & 0.190 & 0.846 & 0.016 \\
Nausea & 1.792 & 0.852 & 3.768 & 0.124 \\
Vomiting & 1.900 & 0.892 & 4.045 & 0.096 \\
Diarrhea & 2.554 & 0.885 & 7.372 & 0.083 \\
Wheeze & 0.387 & 0.090 & 1.670 & 0.203 \\
\hline
\end{tabular}

\section{TABLE 6}

Microorganisms isolated from blood of ambulatory patients with community-acquired pneumonia and the number of these patients who subsequently required admission for treatment of pneumonia

\begin{tabular}{lccc}
\hline & Number & $\%$ & Subsequently admitted \\
\hline Streptococcus pneumoniae & 24 & 58.5 & 2 \\
Staphylococcus aureus & 6 & 14.6 & 6 \\
Escherichia coli & 6 & 14.6 & 4 (plus one pt died in ER) \\
Other & 5 & 12.2 & None \\
Porphyromonas species & 1 & & \\
Neisseria mucosa & 1 & & \\
Peptostreptococcus species & 1 & & \\
Streptococcus anginosus & 1 & & \\
Streptococcus pyogenes & 1 & & \\
\hline
\end{tabular}

ER Emergency room; Pt Patient

4124 patients had blood cultures done. Thus the data indicate that physicians are selective in ordering blood cultures on patients who present to an ER with CAP and who are well enough to be treated on an ambulatory basis.

The current study also showed that the rate of positive blood cultures, at $5.1 \%$ in this group of patients, is relatively high. In a previous study (7), we found that $5(2.1 \%)$ of 233 patients who presented to ER with CAP and had blood cultures done as part of a protocol (thus no selection on the part of the physician) had positive blood cultures. The yield of positive blood cultures for patients who are hospitalized for treatment of community-acquired pneumonia ranges from $6 \%$ to $10 \%$ in most series (1). Because positive blood cultures fre- 
TABLE 7

Patients who were receiving antibiotic therapy at time of presentation to the emergency room (ER) and who had positive blood cultures

\begin{tabular}{|c|c|c|c|c|c|c|}
\hline Study number & Age & Sex & $\begin{array}{c}\text { Antibiotic } \\
\text { at initial visit }\end{array}$ & Microoganism & $\begin{array}{c}\text { Antibiotic at discharge } \\
\text { from ER }\end{array}$ & $\begin{array}{l}\text { Organism susceptible. to } \\
\text { antibiotic at admission }\end{array}$ \\
\hline 600090 & 46 & Male & Amoxicillin & Streptococcus pneumoniae & Cefuroxime & Yes \\
\hline 600606 & 23 & Male & Azithromycin & Staphylococcus aureus & Azithromycin & Yes \\
\hline 121102 & 70 & Male & Ciprofloxacin & $S$ aureus & Cipro & Yes \\
\hline 41707 & 52 & Female & Clarithromycin & S pneumoniae & Clarithromycin & Yes \\
\hline 410923 & 38 & Female & Levofloxacin & S pneumoniae & Levofloxacin & Yes \\
\hline 121331 & 47 & Female & Levofloxacin & Escherichia coli & Levofloxacin & Yes \\
\hline 120791 & 72 & Female & Metronidazole & E coli & * & Not applicable \\
\hline
\end{tabular}

${ }^{*}$ Patient died in ER

quently appear not to result in a change in the management of patients, an argument has been made that they should not be done $(8,9)$. Against this argument is the observation that a positive blood culture for a respiratory pathogen is definite evidence that that pathogen is causing the pneumonia (10). This is very important because a sputum culture positive for a respiratory pathogen only indicates that this is a probable cause for the pneumonia, as colonization of the upper airway with this pathogen could also result in a positive sputum culture. Thus antimicrobial susceptibility testing of pathogens isolated from the blood is important in alerting clinicians to changing susceptibility patterns of respiratory pathogens.

The key then is to perform blood cultures on those in whom they are likely to be positive. While many features were found significantly more often on univariate analysis when the positive blood culture group was compared with the negative blood culture patients, when the data were subjected to multivariate analysis only the inability to produce sputum was significant and that was protective against having a positive blood culture.

In some studies, antibiotic administration before blood cultures is associated with negative results (11). Interestingly, seven (17\%) of our 41 patients with positive blood cultures were receiving antibiotics at the time of presentation. In all instances, the organism isolated was susceptible to the prescribed antibiotic (Table 7). Recently Lonks et al (12) described breakthrough pneumococcal bacteremia in 18 patients who were receiving a

\section{REFERENCES}

1. Mandell LA, Marrie TJ, Grossman RF, Chow AW, Hyland RH, and the Canadian Community-Acquired Pneumonia Working Group. Canadian guidelines for the initial management of communityacquired pneumonia: An evidence based update by the Canadian Infectious Diseases Society and the Canadian Thoracic Society. Clin Infect Dis 2000;31:383-431.

2. Niederman MS, Mandell LA, Anzeuto A, et al. Guidelines for the management of adults with community-acquired pneumonia. Diagnosis, assessment of severity, antimicrobial therapy and prevention. Am J Respir Critical Care Med 2001;163:1730-54.

3. Sturmann KM, Bopp J, Molinari D, et al. Blood cultures in adult patients released from an urban emergency department: A 15-month experience. Acad Emerg Med 1996;3:768-75.

4. Bartlett JG, Dowell SF, Mandell LA, File TM Jr, Musher DM, Fine MJ. Practice guidelines for the management of community-acquired pneumonia in adults. Clin Infect Dis 2000;31:347-82.

5. Kramer MS. Clinical Epidemiology and Biostatistics. Berlin: Springer-Verlag, 1988:159.

6. Fine MJ, Stone RA, Singer DE, et al. Processes and outcomes of care for patients with community-acquired pneumonia. Results from the Pneumonia Patient Outcomes Research Team (PORT) cohort study. Arch Intern Med 1999;159:970-80. macrolide at the time the blood cultures were drawn. All of these isolates were either resistant or intermediately resistant to erythromycin. Our study indicates that breakthrough pneumococcal bacteremia can occur with susceptible strains as well.

Because we did not record the duration of antibiotic therapy before presentation to the ER, we do not know if these breakthrough bacteremias present true failures or insufficient duration of therapy.

Unfortunately, our data indicate that there are no predictors of positive blood cultures for patients who are seen in an ER setting with CAP and are well enough to be treated at home. Thus, the decision to perform blood cultures rests with the judgment of the physician.

ACKNOWLEDGEMENTS: This research was supported by grants-in-aid from Capital Health Authority, Janssen-Ortho Canada Inc, Pfizer Canada, Abbott Canada, and by an establishment grant from the Alberta Heritage Foundation for Medical Research.

We thank the CAP research nurses: JoAnne de Jager, Linda Gardner, Lynne Korobanik, Tammy Pfeiffer, Cynthia Proskow, Sue Marshall, Nancy Baker, Nan Horne and Fredrika Herbert. In addition, we thank the members of EPICORE data management centre at the University of Alberta Hospital.

7. Campbell SG, Anstey R, Ackryod S, Dickenson G, Marrie TJ. Should blood cultures form part of the management of adult patients discharged from the emergency room with communityacquired pneumonia. A prospective observational study. Chest 2003;123:1142-50.

8. Chalasani NP, Valdecanas MAL, Gopal AK, et al. Clinical utility of blood cultures in adult patients with community-acquired pneumonia without defined underlying risks. Chest 1995;108:932-8.

9. Woodhead MA, Arrowsmith J, Chamberlain-Webber R, et al. The value of routine microbiological investigation in communityacquired pneumonia. Respir Med 1991;85:313-7.

10 Fang GD, Fine M, Orleff J, et al. New and emerging etiologies for community-acquired pneumonia with implications for therapy. Medicine 1990;69:307-16.

11. Glerant J Ch, Hellmuth D, Schmit JL, Ducroix JP, Jounieaux J. Utility of blood cultures in community-acquired pneumonia requiring hospitalization: influence of antibiotic treatment before admission. Respir Med 1999;93:208-12.

12. Lonks JR, Garau J, Gomez L, et al. Failure of macrolide antibiotic treatment in patients with bacteremia due to erythromycinresistant Streptococcus pneumoniae. Clin Infect Dis 2002;35:556-64. 


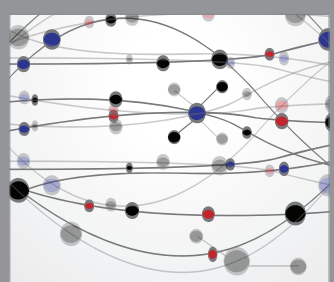

The Scientific World Journal
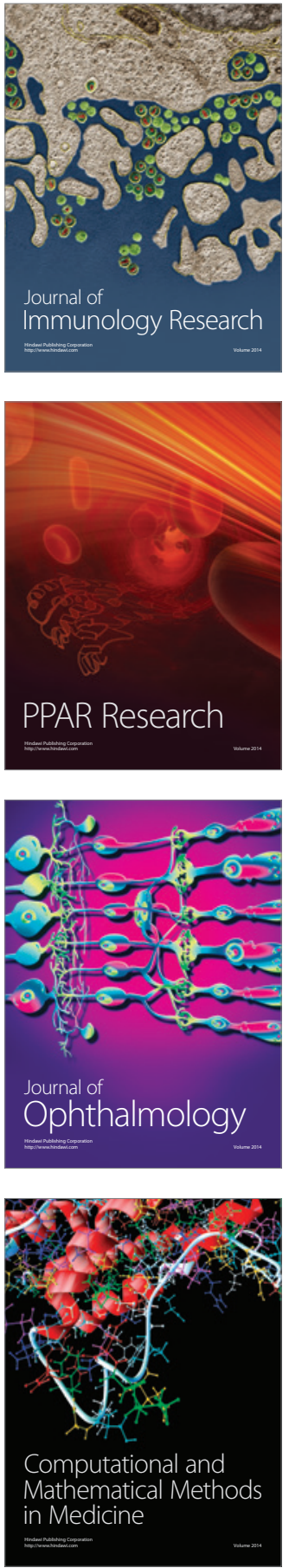

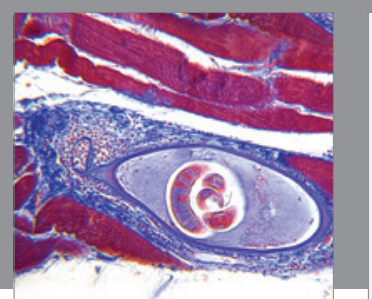

Gastroenterology Research and Practice

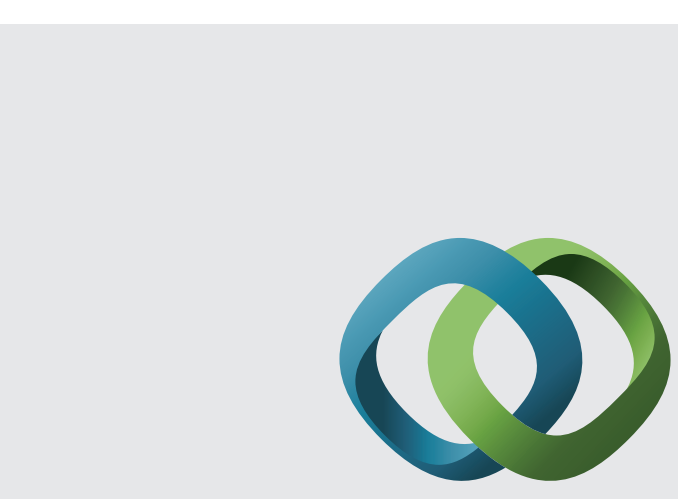

\section{Hindawi}

Submit your manuscripts at

http://www.hindawi.com
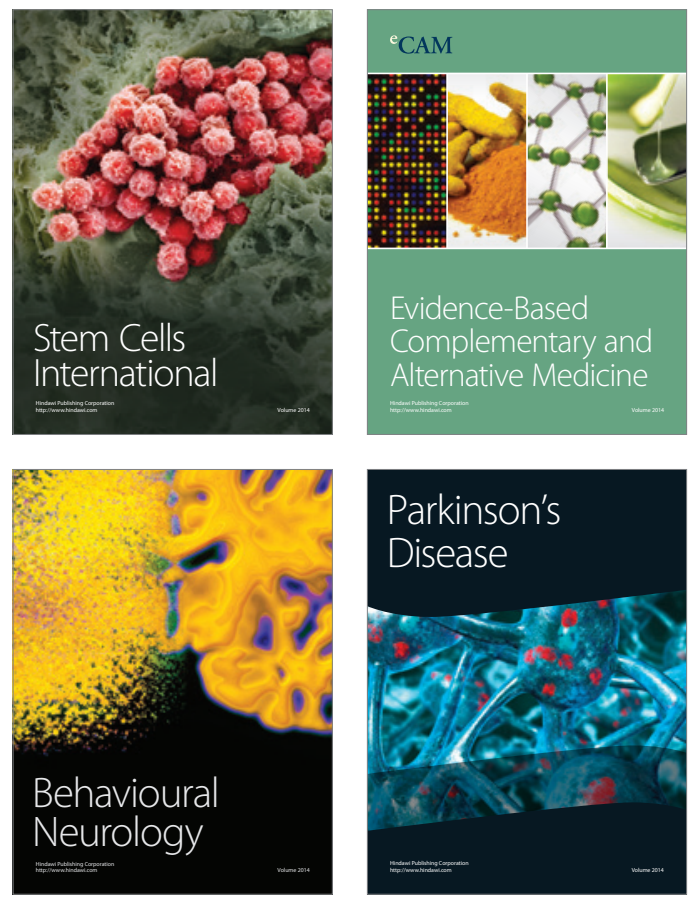
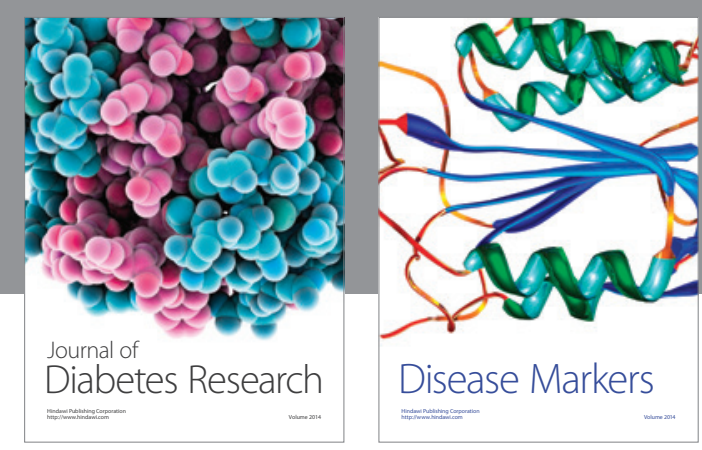

Disease Markers
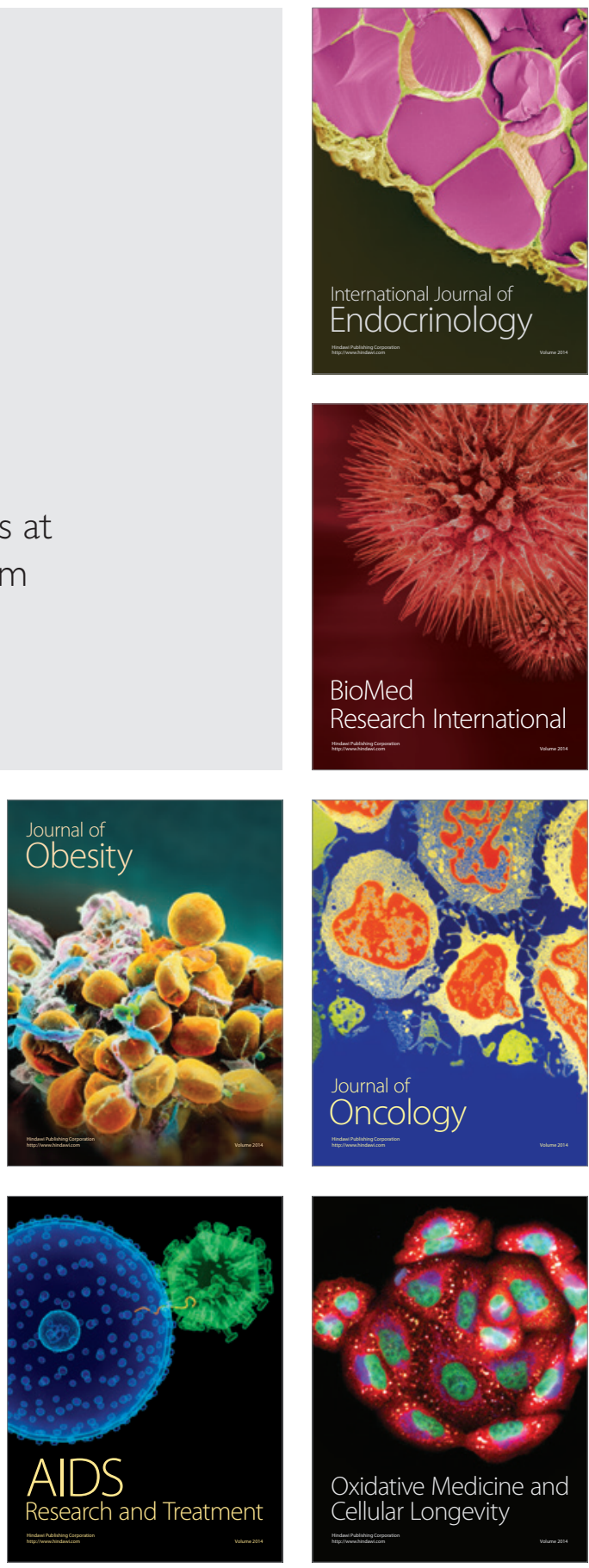